\title{
14 NAMING THE DEAD HEART: HILLIER'S MAP AND REUTHER'S GAZETTEER OF 2,468 PLACENAMES IN NORTH-EASTERN SOUTH AUSTRALIA
}

\author{
Philip Jones
}

This paper is about the Hillier Map of Aboriginal placenames of north-eastern South Australia. By 1904, when this map was drawn (Fig. 1), the region east and north of Lake Eyre had been largely explored and surveyed, its principal features named and the country had been divided and then subdivided for pastoral purposes. A couple of years earlier at the height of a severe drought, the last Aboriginal people living beyond the bounds of European influence had chosen to leave their Simpson Desert home. ${ }^{1}$ Their destinations were the remote cattle stations such as Alton Downs, Cowarie and Macumba, established on the fringes of the Desert. These isolated settlements, run by Europeans who came to rely almost entirely upon Aboriginal knowledge and expertise in this harsh country, became the foci of subsistence and sociability for remnants of Wangkangurru, Ngamini, Yarluyendi and related groups. Their choice contrasted to that of the greater number of Aboriginal people from the region who had progressively 'come in' to the Killalpaninna mission station on the Cooper since its foundation in 1866. It is the descendants of those small and vulnerable mixed communities, comprising representatives of different language groups, who have maintained an unbroken presence in the northern part of the region until the present day and who preserve the greater store of knowledge about Aboriginal placenames. ${ }^{2}$

In contrast, the corporate identity of the much larger and apparently more homogeneous community of mainly Diyari speakers at Killalpaninna Mission - where the Hillier Map was made - is considerably less evident.

\footnotetext{
1 Hercus $(1985 ; 1986)$.

2 Jones, (1991); see also, for example, Hercus and Potezny (1990).
}

L. Hercus, F. Hodges and J. Simpson, eds, The Land is a Map: placenames of Indigenous origin in Australia, 187-200. Canberra: Pandanus Books in association with Pacific Linguistics, 2002. 


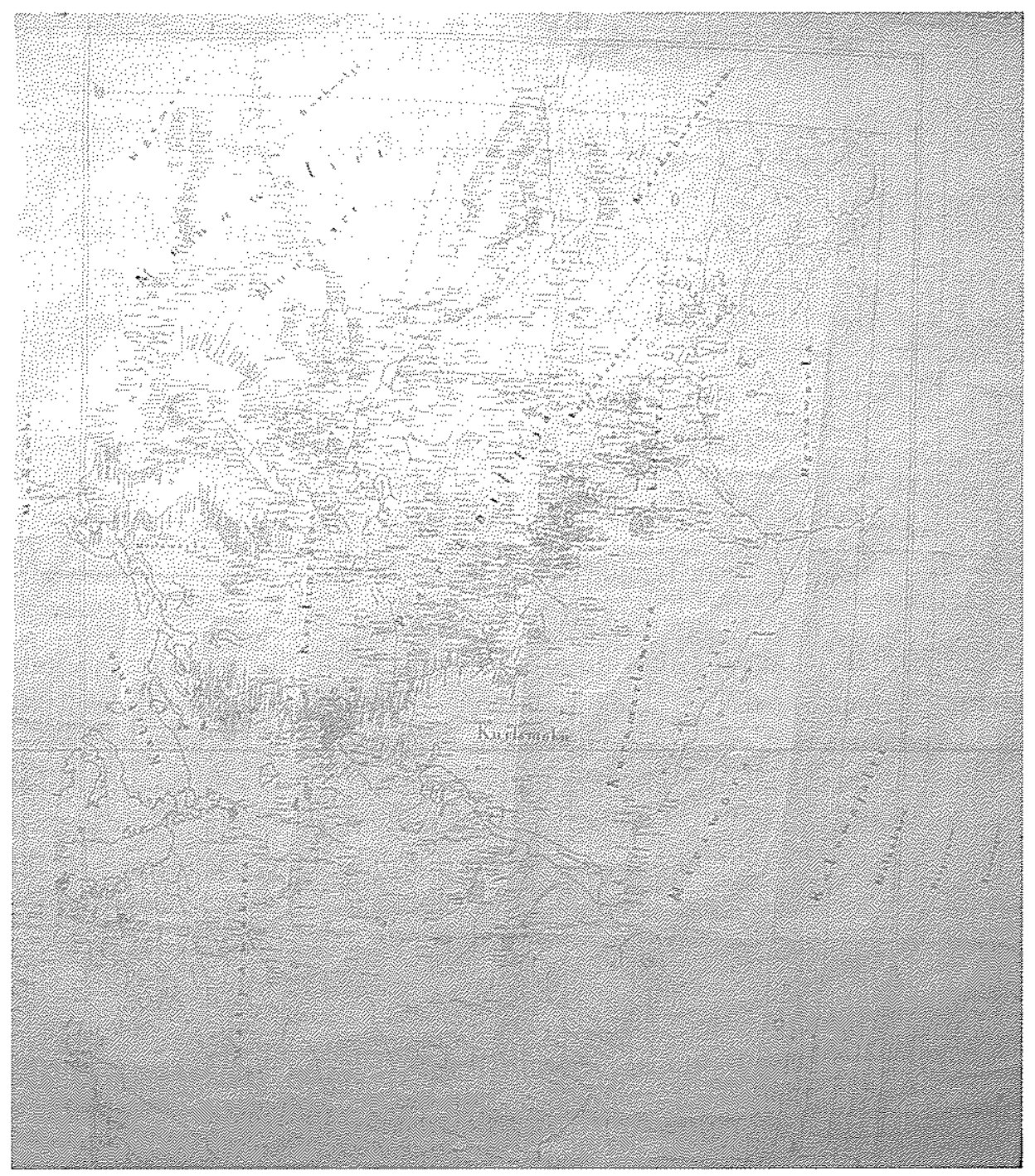

Figure 1: The Hillier Map, drawn in 1904 by schoolteacher Henry Hillier, at Killalpaninna Mission, Cooper Creek, South Australia. South Australian Museum

The Hillier Map is an extraordinary document, as much for what it excludes as for its dense profusion of named Aboriginal sites. It contains approximately 2,500 placenames probably more than the 2,468 listed in the accompanying gazetteer compiled by Pastor J.G. Reuther as volume VII of his Diyari manuscript. ${ }^{3}$ These names are inscribed on silk in Henry Hillier's minute ink letters over his tracing of an 1890s 1:500 000 pastoral plan. ${ }^{4}$ But while this tracing includes the colony's boundaries, the delicate dotted lines of the Birdsville and Strzelecki Tracks and some mail routes to Lake Hope, Cowarie and other stations, these traces of European influence are exceptional. The town of 'Birdsville' constitutes the map's sole

3 Reuther, J.G. (1981).

4 Hillier (1904). 
European placename. The larger town of Marree is marked only by its placename Marina, Innamincka by Jidniminka, and Lake Eyre itself by the larger inscription, KATITANTA. Although Hillier appears to have retained European trig points (a scattering of small triangles across the extent of the region) - probably as references for plotting placenames - crucial landscape features are barely evident. The drainage system which dominates European maps has all but disappeared under the density of Aboriginal placenames.

The Hillier Map more than negates the image of emptiness and desolation conveyed by European maps of the region. That perception of a desert void, generated by Edward Eyre, Charles Sturt, Peter Warburton and others, was subsequently reinforced by twentieth-century explorers such as Cecil Madigan whose 'Dead Heart' appellation is now entrenched in popular consciousness. The most promising vistas observed by Charles Sturt's party during his epic struggle to penetrate this region during $1844-45$ were revealed as mirages. Marooned at its edge by a withering drought, Sturt neither dignified his forced camp with a European proper noun nor its Aboriginal name. At Depot Glen his party was, in his words, 'bound by the heat as fast as if we were amidst the eternal Ice at the Poles'. ${ }^{5}$ This site seemed to him a non-place, the nineteenth-century explorer's equivalent of an anonymous airport lounge; Sturt waiting for a connection. The expedition's boat was abandoned unused at the edge of the Simpson Desert and fittingly it was the inland sea that provided the most telling metaphor for this wasteland environment. Sturt and subsequent explorers conceived of the desert as an ocean; a 'perfect sea of dunes', 'trackless', 'as far as the eye can see', were phrases used in their descriptions.

But like a sea, the Simpson Desert was both barrier and means of communication. Different language groups and differing kinship systems characterised groups bordering it to the east and west, north and south. And yet these groups were not self-contained entities. People married in and out and traded goods and ceremonies with each other. To varying degrees they also spoke each other's languages and used each other's sites and placenames. They followed defined routes across the Desert, navigating from mikiri to mikiri well as though from island to island. Lines of mythology and of genealogy crossed the Desert, binding individuals and groups together across hundreds of kilometres. Here the analogy ends, for Aboriginal people knew the north-eastern deserts intimately as their home rather than as the forbidding landscape perceived by Europeans. As Luise Hercus put it,

it was the home of people who were familiar with every dune, every claypan and swamp: they lived there on a permanent basis. They did not just travel from mikiri to mikiri, every salt lake, all the bigger sandhills and claypans had names. It was simply their home.

(L. Hercus, pers. comm.)

There is no doubt that Sturt's attitude towards this region as a series of stony and sandy deserts separated by dry waterholes and creek-beds, which had to be traversed in order to reach his desired goal, meant that it never became an object of investigation in its own right. It was an impediment, country to be passed over. Its Aboriginal inhabitants were interrogated not about their own country and its named features, but only about the country beyond. In this sense, Sturt wasted most of his opportunities with Aboriginal people visiting his camps and with those encountered during his party's dead-end reconnaissance expeditions. He did not obtain a single Aboriginal placename for sites on the Strzelecki, Cooper, Diamantina or Eyre

Sturt (1844-46). 
Creeks and made no apparent effort to come to grips with Aboriginal languages of the region once his own Aboriginal guides (from the Darling) moved beyond their linguistic range.

Neither Eyre, on his expedition of 1841, nor Goyder (1857), Burke and Wills (1861-62), Warburton (1866) or Lewis (1874) added more than a handful of additional Aboriginal names. Of these explorers Lewis was perhaps the most dependent upon Aboriginal guidance. He used at least two interpreters who knew sufficient English to communicate placenames accurately, but his 1874-75 map is a sad reflection of his capacity to absorb this information. ${ }^{6}$ Punctuating his route are 'Christmas Water', 'Gardiner's Waterhole', 'Camel Water', 'Yellow Waterhole' or simply 'Waterhole' and several examples of 'Native Well'. The site 'Tommy's Well', named after the Ngamini or Wangkangurru guide who had 'a good smattering of English having been with the telegraph parties for some time and was very useful as a guide and interpreter', was the closest Lewis came to applying an Aboriginal name during his traverse to the north of Lake Eyre (Lewis 1876).

The surveyors and pastoralists who followed Lewis made the greatest advance in recording placenames for this north-eastern region. Most notable was William Cornish, whose 1879 survey of the Warburton and Kallakoopah Creeks covered some of Lewis's ground and added more than a dozen new Aboriginal names to maps. Cornish does not mention it in his report to the Surveyor General, but it is probable that he relied partly upon the first owner of Cowarie Station, a German, August Helling. Later, both Cornish and another German based at Helling's Cowarie Station, W.J. Paull, contributed Aboriginal vocabularies from the Warburton to E.M. Curr's 1886 volume (Cornish 1886; Paull 1886). By this time Helling's knowledge of the region's Aboriginal placenames was supplemented through his role in pioneering the mail run to Birdsville (Litchfield 1983:5). In fact, Helling emerges as a possible important source for the Hillier Map; his German background led to close contact with the Killalpaninna Mission during the 1870s and 1880s, if not beyond. Writing in 1934 from his store at Mulka on the Birdsville Track, George Aiston acknowledged that Helling was 'an independent observer and was a reliable authority [who] lived in the heart of Wongkonguru country', further maintaining that Reuther's manuscript records of the Aboriginal peoples of the Cooper and Warburton were 'nearly all Helling'.

The Killalpaninna missionaries had the incentive and means to augment European maps of the Aboriginal landscape surrounding them from the time of their arrival at Bucaltaninna, Kopperamanna and Killalpaninna in 1866. Their efforts to "enter the mental world of the heathen' could succeed only through an understanding of the various languages spoken in the region and by orienting themselves in relation to those complexes of sites which distracted Aboriginal attention, away from the mission. While this broader project did not take final shape until Reuther's time (accompanying his ambitious investigations into the range of beliefs relating to the mythological landscape), an early priority was a meaningful map of the 'mission block itself'. Two versions of such a map apparently exist, dating from the early 1870 s [fig. 2]. ${ }^{8}$ The northern section of a poor copy of one version is reproduced below,

${ }^{6}$ Lewis (1876).

7 G. Aiston to W.D. Gill, 26 June 1934. Aiston, G. (1920s-1940s) MS. Correspondence with W.H. Gill. A2535-A2537, Mitchell Library, Sydney. Note that Helling was in fact living in traditional Ngamini, not Wangkangurru, country.

8 One map has been sighted in the Lutheran Archives (J. McEntee, pers. comm.), another is in the Anthropology Archives, South Australian Museum (AA266). 
showing the way in which the Aboriginal landscape was becoming merged with a European, mission landscape. The Killalpaninna lake and mission station are evident at the top of the map. Wells, horse-paddocks, sheds and roads are marked together with a concentration of Aboriginal sites along the Cooper, prefiguring the density of placenames on the Hillier Map.

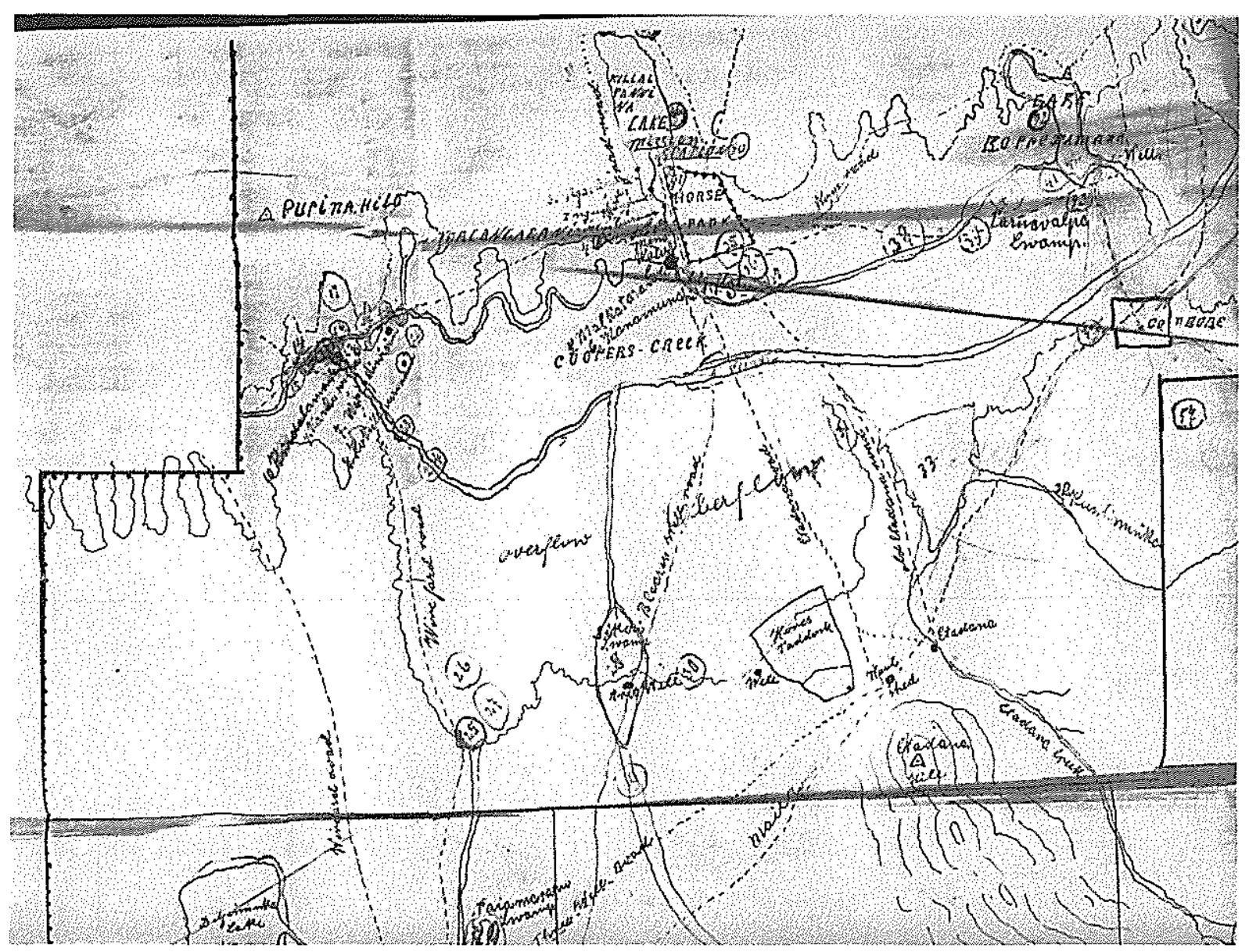

Figure 2: Detail from Gason's map of the Killalpaninna 'mission block', c.1870.

Anthropology Archives, South Australian Museum

We can assume that the ringed figures on this map refer to a list of Aboriginal placenames, perhaps with expanded text. Intriguingly, while the map obviously refers to the territory of the mission and includes some German text, the bulk of the annotations seem to be in the hand of Samuel Gason, the police-trooper who had preceded the Lutherans in the region, based consecutively at Lake Hope and Kopperamanna until posted to Barrow Creek in 1873. Gason's subsequent correspondence with Alfred Howitt suggests that, like the missionaries, Gason had elevated the Diyari as a corporate entity, subsuming separate references to other language groups at the Lutheran mission under that general heading. ${ }^{9}$

By the 1880 s even recently arrived pastoralists in the Cooper and Warburton region were well aware of the density of Aboriginal placenames, even though Lewis's map and the first

Gason to Howitt, 1870s. A.W. Howitt Correspondence, Australian Institute of Aboriginal and Torres Strait Islander Studies, Canberra. 
general pastoral plans remained the only readily available maps. The unpublished record of the 1882 and 1883 horseback tours of inspection by pastoralists K. Robinson and a Mr Taylor along the Warburton Creek west of Cowarie shows that a reliable set of placenames was becoming essential when establishing sources of water and feed for stock. In contrast to Lewis's bland and meaningless naming, these aspiring pastoralists could not afford to abandon the precision and relevance of Aboriginal names. ${ }^{10}$ Again, it is likely that Helling was the source of these names used by Taylor and Robertson. The Taylor journals offer possibilities for confirming particular placenames on the Hillier Map. Taylor documents two expeditions by horseback from Cowarie Station along the Warburton and notes details of each halt, a mileage, and the Aboriginal names of waterholes and springs. Where these coincide with the names on the Hillier Map, it should be possible to localise those names, particularly where other known reference points are included. The highlighted names on Figure 3 are those Hillier sites along the eastern section of the Warburton Creek visited by Taylor and Robertson, providing an indication of the value of interrogating archival records for corroborative placename detail.

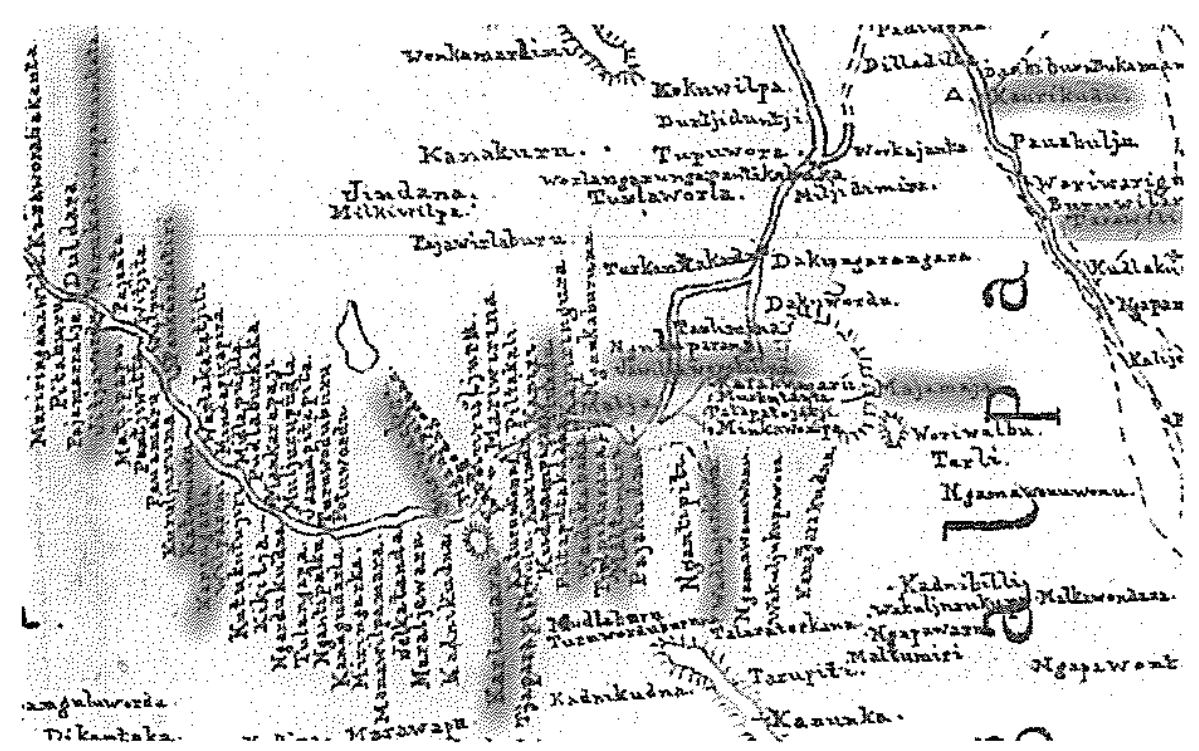

Figure 3: Annotated detail of Hillier Map along eastern Warburton Creek, with placenames identified from the 1882-1883 Taylor journals

An inevitable corollary of this European reliance upon the Aboriginal landscape was that these names became Anglicised (or perhaps 'Germanised') to a degree. Such changes occurred through constant use by European speakers rather than through any concerted alteration. The Lutherans' own attempt to change the name of Killalpaninna (Kirla-wilpa-ni-nha $=$ vagina) to the benign Hebrew 'Bethesda' ('healing pool') was a conspicuous failure, except in genteel Lutheran circles.

\footnotetext{
10 An accurate transcription has not yet been made of this journal which is in the possession of a family member. It contains several Aboriginal placenames along the Warburton which are otherwise known only from the Hillier Map. Copy in possession of author.
} 


\section{THE HILLIER MAP AS A RESEARCH TOOL}

Until recently the Hillier Map has operated most effectively at a symbolic rather than an informational level. The fact that the map contains 2,500 Aboriginal placenames, and seems to have resulted from a remarkable if mysterious partnership, has overshadowed the information that these names carry or the issue of their exact location. Despite that, two quite different lines of research have focused upon the map, gleaning valuable information from it. The first, and most productive of these has been the meticulous site-recording work of Luise Hercus and Vlad Potezny, undertaken particularly during the 1980s. Their work has undoubtedly illuminated more of the map's deficiencies than its virtues, but has shown that the map can function as a source of information which complements and informs other sources, including first-hand data from Aboriginal informants. Hercus's 1987 paper, 'Just one Toa', also drew attention to the particular, if inconsistent, relationship between the Hillier Map, the Reuther placename volume which describes the names on it, the Reuther toas which refer to and symbolise these places, and the other Reuther manuscript volumes (Hercus 1987). Hercus's search for the important Wangkangurru ceremonial site of MaRaru was ultimately successful in spite of, rather than because of, the Hillier Map. The site appears on the map as one entry in an inaccurate and unlocalised list of sites, placed almost at random in the Simpson Desert.

Hercus and Potezny's 1990 paper, dealing with the section of the Hillier Map south of Birdsville along the Diamantina and the Mulligan channels, provides even more salutary reading for those who might imagine it possible to 'simply go out and follow the map, use the information from the [Reuther] volumes and locate all the important Aboriginal sites in the north-east of South Australia' (Hercus \& Potezny 1990:139). In fact, as the authors make clear, the map's primary value lies in its corroborative importance when used in conjunction with other historical sources, evidence provided by Aboriginal informants, and field research. Their paper gives several comprehensive examples of how this blend of careful research can supply meaning and exact locations to the names on the Hillier Map.

Hercus and Potezny's work confirms that the Hillier Map was largely a desk-based exercise, probably undertaken by both Reuther and Hillier working together to fix the generalised localities of sites in one region after another. But the fact that the numbered sequences of sites in Reuther's volume VII often appear on the map in a similar sequence suggests not only the ethnographers' working practice; it also indicates that Aboriginal informants were supplying their own sequences of sites. Whether those sequences correspond to the course of particular Dreamings, or to an imagined journey through familiar country, may be tested through further analysis. Limited research into this question suggests that Hillier and/or Reuther used existing mapped topographic references, such as water features and trig points to make cartographic sense of the data being supplied to them by their informants. In areas of the base map where such topographic markers did not exist, their cartographic rendering of this information is barely distinguishable from a list of names superimposed on a blank. This process is exposed most clearly in the remotest areas from the mission itself, particularly in the Simpson Desert and along and adjacent to the Diamantina and Mulligan channels. Further, it is often difficult to be sure whether the indicated site is at the beginning or the end of a placename, as Hillier used locative dots for a minority of sites. His practice of finishing each name with a tiny dot is a trap for the unwary. Where the names clearly refer to sites along a watercourse or around a lake, this is less of a problem. Elsewhere 
the task is much more difficult: as Roderick Wilson observed (1981:6), a single Hillier placename may cover 15 kilometres of country.

Even on the Warburton and Cooper channels, probably well known to mission staff, Hillier seems to have paid as much attention to fitting the names neatly on the map in geographical sequence without overlapping, as to fixing their exact location. For example, in that part of the Warburton that bristles most thickly with his names, Hillier allowed just enough space for each name to be read individually (see Fig. 3). But while this inevitably imparts a distortion to the map, the Taylor journals' record of site distribution along the north and south banks of the Warburton matches that of Hillier's.

Nevertheless, in these stretches of the Warburton and Cooper, where the names are so thick that the meanderings of the rivers themselves are often obscured, Hillier was placing a name on every twist and turn. This itself suggests possibilities for a process of retrieving lost placenames by informed guesswork, even without the possibility of confirming those guesses through Aboriginal informants. An occasional correlation with named Aboriginal sites on other maps - particularly the 1890s pastoral plans, but also including the recent 1:250 000 series - may provide the basis for firmer attributions from the Hillier Map. The accompanying descriptions in the Reuther placename volume may provide an additional corroboration, although these can rarely be interpreted as site-specific. This approach has been attempted by this author and John McEntee on the Warburton Creek west of Cowarie, for example, using a combination of the Hillier Map, the Taylor journal and the Helling and Cornish maps, and at Lake Hope on the Cooper. This will be the only possible approach in the future, given that opportunities for carefully fitting all the jigsaw pieces of song-verse, Aboriginal knowledge and memory, field observation, archival fragment and map-name together have already vanished.

The Hillier Map has potential research value of another order. This line of enquiry was first explored during the 1920 s by Norman Tindale and more recently by the geographer Roderick Wilson (Wilson 1981). It involves treating the Hillier Map as an artefact in its own right, revealing a pattern of information which, despite its shortcomings as an accurate linguistic and ethnographic source, nevertheless illuminates the historical context of the map's creation. Norman Tindale was the first to realise that each of the Reuther placenames could be coded according to the tribal affiliations documented in volume VII of his manuscript (Reuther 1981). By concentrating upon this association, rather than upon any exact plotting or analysis of the placename itself, an impression of the broader mosaic of language-group affiliations might be gained. Tindale attempted this by allotting a colour to each tribal group and underlining each placename in ink of that colour on a large photo-mosaic of the map. The result, rather tattered and illegible now after seven decades, gives a remarkable insight into the map as a cultural artefact of Aboriginal language group affiliations in the eastern Lake Eyre region. Of course, as Luise Hercus has pointed out, this pattern of affiliation may well be flawed, as it relies upon the language group attributions made by Reuther and/or Hillier. We cannot be certain, for instance, that their attributions related to the actual site's affiliation, or to the language group of their particular informants, who may have been describing sites belonging to other groups. It is worth noting, though, that while the sites associated with toa names, recorded in volumes XII and XIII as well as in volume VII, often differ fundamentally in their Dreaming ancestor affiliations and in other details (suggesting different informants), their language group affiliations do not vary. 
The recent digitisation of volume VII, supervised by Bill Watt of the Geographical Names Board, has enabled the most numerous language group affiliations of the Hillier placenames to be viewed as a table (see Fig. 4).

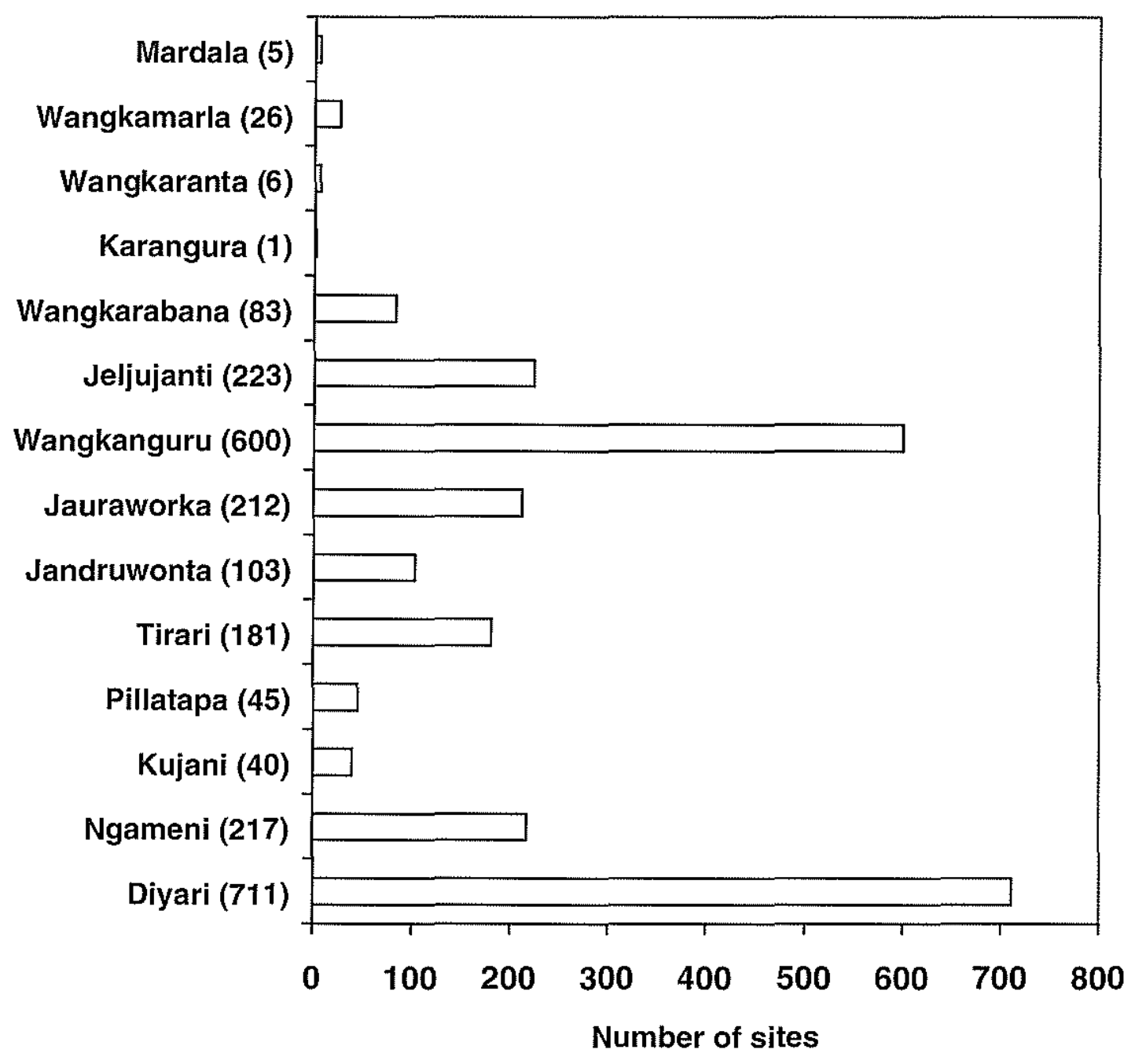

Figure 4: Numbers of placenames on the Hillier Map by language-group affiliation (Reuther's orthography)

The data are striking in one immediate sense: we are reminded that despite the Lutheran missionaries' commitment to the Diyari and Reuther's characterisation of his ethnographic work as a study of that single group, the reality was far different. The tally of Diyari placenames is almost equalled by Wangkangurru, and both together represent only slightly more than half of the recorded total. Despite its location in Diyari heartland, by the $1890 \mathrm{~s}$ Killalpaninna was a cosmopolitan place, a focus for most of the major language groups of the region. It is reasonable to assume that the men and women contributing data to the Hillier 
Map were drawn from this range of groups, and that they were attributing their own language group names to their own sites. Luise Hercus has drawn attention to errors in this record, or to sites that may have had shared affiliations of which only the lesser was recorded by Reuther (the MaRaru site is an example, see Hercus 1987). But broadly speaking, the coloured mosaic which can be drawn of the Hillier names in digital format should reflect the ethnographic reality of the accepted divisions - and, perhaps most interestingly, interpenetrations - of the region's language groups. This mosaic of language group/site distribution has been encoded in the Hillier Map and the Reuther manuscript since these documents were created, but it is unlikely that either the German missionary or the English schoolteacher was aware of the extent to which this 'pattern in the carpet' might be revealed.

Figure 5 shows a Hillier Map section of the Coongie Lakes region, incorporating border territory of the Diyari (south-western), Yawarrawarka (northern) and Yadliyawarra (south-eastern) groups; the superimposed 'boundaries' mark the relatively sharp divisions between language group-affiliated sites. The interpenetration of site affiliations here is minor compared to the region just a few kilometres to the west, where a mixture of Yarluyendi, Ngamini, Yawarrawarka, Diyari and even Wangkangurru-affiliated sites is recorded by Reuther and Hillier. The map contains several contrasting vignettes of this kind - each requiring detailed analysis, particularly by linguists. 


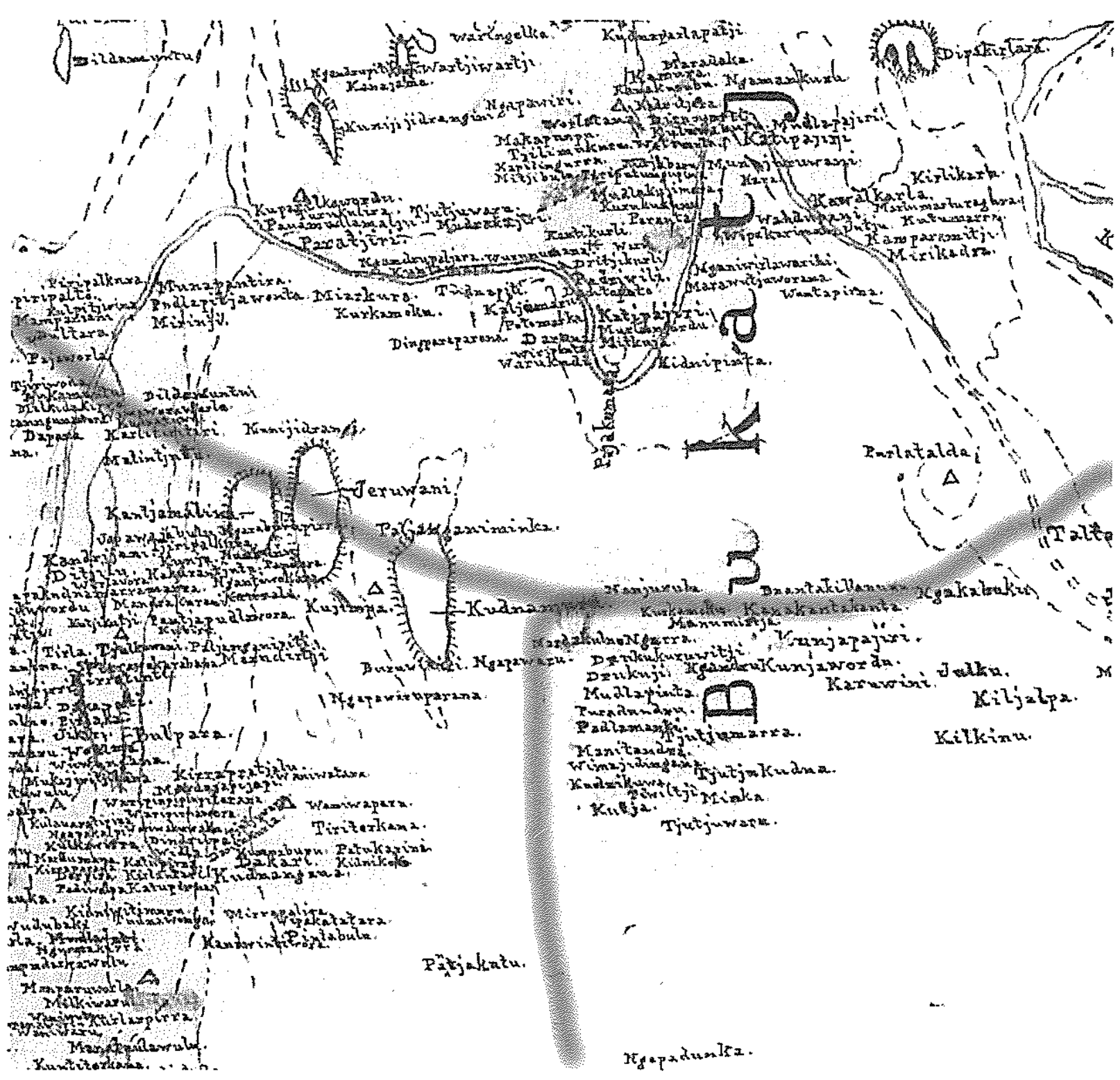

Figure 5: Section of Hillier Map showing abutting 'territories' associated with Yawarrawarka (northern), Yandruwantha (south-eastern) and Diyari (south-western) placenames. Boundaries superimposed.

Wilson's 1981 thesis indicates what may be gleaned from the Hillier Map at other, broader levels of analysis. Again, his plotting of Hillier placenames affiliated to particular mura-mura or Dreaming Ancestors reflects Reuther and Hillier's data, rather than ethnographic reality. But following his lead, the digitisation of the Hillier Map will eventually enable a more accurate analysis of these site 'sets' associated with the various mura-mura.

A further problem to be faced here is that of the uneven fit between the sets of mura-mura mentioned in Reuther's volume VII, his toa volumes (vols XII and XIII) and two other volumes concerning religion and legends (vols X and XI). Several mura-mura discussed in the toa volumes do not appear in the other volumes, and vice versa. It appears that Reuther may not have understood that the same Ancestor could be referred to in several ways, and by various cryptic terms. Apparent discontinuities between the data relating to the mura-mura 
recorded in these different volumes also suggest that he may have been working with different informants at particular times, and so was obtaining varying accounts of the same Dreaming from different perspectives. It is therefore not a straightforward matter to simply digitise Reuther's data and match it to the mapped placenames. Even so, with the eventual digital coding of all Hillier's placenames according to the Ancestral and language group affiliations ascribed to them in volume VII, it may be possible to interrogate data contained in the other volumes in an effort to identify some meaningful, previously hidden correlations. In the process, as John McEntee's research has revealed (pers. comm.), these other volumes contain a quantity of other placenames not referred to in volume VII, and possibly not recorded on the map.

One productive line of research may be to highlight (if not to clarify) the relationship between the Hillier Map, the placenames volume and volumes XII and XIV, which both concern the toas. Each of these three volumes refers directly to named sites appearing on the Hillier Map, but in different terms. The variation between the descriptions in volumes XII and XIII is usually so slight as to suggest that this may be accounted for by the process of transcription itself, especially if Reuther was attempting to improve his written expression, in order to promote his collection for sale. But the contrast between these accounts of toa sites and the corresponding placename descriptions in volume VII is marked. Most strikingly, the Ancestor associated with the toa site is rarely described as the same Ancestor for that site in volume VII. This aspect requires more detailed research, but it is worth noting that the preponderant 'set' of toa Ancestors does not mirror the most numerous set of volume VII site Ancestors.

These differences may simply reflect Reuther's reliance upon different groups of informants for his site and toa data. The range of language group and mythological alignments among the Aboriginal community based at Killalpaninna may well account for such consistently different emphases and explanations, and once the etymology of the Ancestor names is unravelled, these differences may also make sense. Nevertheless, this strong inconsistency reminds us of the controversial origins of the toas themselves and the likelihood that they emerged as innovative elements of a mission-based material culture responding to intense demand for elaborated artefact forms (see Jones \& Sutton 1986). That said, the toas' references to particular sites and Dreamings are indisputably authentic. In fact, these objects can be regarded as 'sculptural placenames', not merely in the sense that they often operate logographically as symbolic embodiments of named sites or the ancestral action taking place there, but because each toa represents a site on the Hillier Map.

The Reuther toas are known to have been made on Killalpaninna Mission itself, probably during late 1903 or early 1904. This mapped distribution of 'toa sites' is a further reminder that the Aboriginal individuals involved in the creation of the toas were drawing on the wide extent of their territorial knowledge, despite a growing dependence upon the single site of the Lutheran mission. But more importantly, with the insight that they provide into the heroic episodes of eastern Lake Eyre Histories or Dreamings, the toas offer a useful reminder of the distinction between the Hillier Map and a conventional European map of the Australian desert (see also Sutton 1998:383-384). There is a deceptive uniformity to the Hillier placenames, a sense that all are on a level and weighted to the same degree of meaning, unlike a European map where the features are differentiated, separating destinations from impediments, centres from outliers, hills from valleys. It is the Reuther manuscript that provides that key for 
differentiating the Hillier placenames, enabling us to see that the dynamic which underlies and invigorates the placenames is that of Ancestral action, multiple imprints left on the landscape by a legion of mura-mura pursuing their individual and interlocking destinies. In 1904, even if some of this meaning and the Aboriginal taxonomy underlying it was apparent to Reuther and Hillier, it was clearly impossible for them to represent it graphically. A century later, using the clues embedded in the Reuther manuscript and the essential research contribution of linguists and Aboriginal people, it may be possible to redraw Hillier's Map with that in mind.

\section{REFERENCES}

Cornish, William H., 1886, Cooper's Creek \& Warburton River. In E.M. Curr, ed., The Australian Race. Vol. II: 22-23; 24-25; 28-29. Melbourne, John Ferres.

Hercus, Luise, 1985, Leaving the Simpson Desert. Aboriginal History 9(1):22-43.

- 1986, The end of the Mindiri people. In L.A. Hercus and P.J. Sutton, eds, This is What Happened, 182-192. Canberra, Australian Institute of Aboriginal Studies.

- 1987, Just one Toa. Records of the South Australian Museum 20:59-69.

Hercus, Luise and Vlad Potezny, 1990, Locating Aboriginal sites: a note on J.G. Reuther and the Hillier Map of 1904. Records of the South Australian Museum 24(2):139-151.

Hillier, Harry, 1904, Map of 2,468 place-names north and east of Lake Eyre. AA266, South Australian Museum.

Jones, Philip, 1991, Ngapamanha: a case study in the population history of north-eastern South Australia. In P. Austin et al., eds, Language and History: essays in honour of Luise A. Hercus, 157-173. Canberra: Pacific Linguistics.

Jones, Philip and Peter Sutton, 1986, Art and Land: Aboriginal sculptures of the Lake Eyre region. Adelaide: South Australian Museum.

Lewis, John W., 1876, Journal of Mr Lewis's Lake Eyre expedition, 1874-75. South Australian Parliamentary Papers 19:1-42.

Litchfield, Lois, 1983, Marree and the Tracks Beyond in Black and White. Adelaide, the author.

Paull, W.J., 1886, Warburton River. In E.M. Curr, ed., The Australian Race. Vol: II, 18-21. Melbourne: John Ferres.

Reuther, Johann G., 1981, The Diari vols 1-13. Translated by Philipp A. Scherer. Vol. 5 translated by T. Schwarzschild and L.A. Hercus. AIAS Microfiche No. 2, Canberra: Australian Institute of Aboriginal Studies. Original volumes in South Australian Museum, AA266.

Sturt, Charles, Journal of 1844-46 expedition, entry for 13 January 1845. Microfilm, Mortlock Library of South Australiana, Adelaide. 
Sutton, Peter, 1998, Icons of country: topographic representations in classical Aboriginal traditions. In D. Woodward and G.M. Lewis, eds, Cartography in the Traditional African, American, Arctic, Australian and Pacific Societies. The History of Cartography. Vol. 2, Book 3: 353-386. Chicago: University of Chicago Press.

Wilson, Roderick S., 1981, Geography and the totemic landscape - the Dieri case: a study of Dieri social organisation including territorial organisation. BA Hons thesis, University of Queensland. 